\title{
AVALIAÇÃO DE PARÂMETROS ULTRASSÔNICOS EM AÇOS INOXIDÁVEIS EXPOSTOS A CICLOS ISOTÉRMICOS
}

\author{
EVALUATION OF ULTRASONIC PARAMETERS IN \\ STAINLESS STEEL EXPOSED TO ISOTHERMAL \\ CYCLES
}

\author{
Cláudia Teresa Teles Farias* \\ Teodorio A. S. de Oliveira* \\ Maria Doroteia Costa Sobral ${ }^{*}$ \\ Moisés Araújo Oliveira* \\ Ygor Tadeu Bispo dos Santos*
}

\begin{abstract}
RESUMO
Os aços inoxidáveis duplex e austeníticos apresentam excelentes propriedades mecânicas e resistência à corrosão, sendo amplamente utilizados em plantas químicas e petroquímicas. Entretanto, quando submetidos a altas temperaturas de serviço, como processo de soldagem, pode ocorrer variação das propriedades mecânicas em função da precipitação de fases secundárias que são responsáveis pela fragilização do material e diminuição da resistência à corrosão, além do fenômeno da sensitização. Técnicas não destrutivas são utilizadas na inspeção de equipamentos e podem ser aplicadas na avaliação de materiais quanto ao surgimento e a evolução de falhas decorrentes de alterações microestruturais. Dentre as técnicas não destrutivas, a ultrassônica é uma das mais empregadas na inspeção industrial para identificação e caracterização de materiais, tais como, a determinação de atenuação sônica, constantes elásticas, corrosão, tensões residuais, entre outras. Por apresentarem uma estrutura anisotrópica, a microestrutura destes aços inoxidáveis é responsável pela variação da atenuação e velocidades ultrassônicas às quais estão relacionadas ao tamanho e orientação dos grãos, respectivamente. Este trabalho tem como objetivo principal o estudo da influência da temperatura em corpos de prova em aços inoxidáveis com o intuito de correlacionar a atenuação sônica com a variação do tamanho do grão, para o aço austenítico AISI 316L, e a precipitação de fases secundárias, para o aço duplex UNS S31803, uma vez que a correlação do tamanho do grão com a atenuação para este último aço, não apresentou variações significantes. O parâmetro ultrassônico de atenuação em função da frequência mostrou-se uma ferramenta útil para avaliar as transformações microestruturais das amostras em aço inoxidável austenítico 316L e duplex UNS S31803. O procedimento experimental utilizado para a determinação das velocidades sônica transversal e longitudinal foi satisfatório quanto aos resultados encontrados, ao serem confrontados com os teóricos. Para os aços austeníticos foi verificado que a atenuação mostrou-se dependente do
\end{abstract}

*Instituto Federal de Educação, Ciência e Tecnologia da Bahia, e-mail: farias@ifba.edu.br 
tamanho do grão. Em relação as amostras em duplex, não houve correlação do tamanho de grão com a atenuação, provavelmente há variações insignificantes quanto ao diâmetro médio do grão da austenita. A redução do tamanho de grão austenítico foi devida ao aumento da fase ferrítica, onde são precipitadas as fases secundárias responsáveis pelo aumento da dureza detectada pelo ensaio Vickers.

Palavras-chave: Aço Duplex. Aço Austenítico. Atenuação. Ensaio Ultrassônico.

\begin{abstract}
Duplex and austenitic stainless steel has excellent mechanical properties and corrosion resistance; it is widely used in chemical and petrochemical plants. However, at high temperatures, such as welding, mechanical variations might occur due to secondary phases of precipitation, which are responsible for material brittleness and the reduction of corrosion resistance, in addition to the sensitization phenomenon. Non-destructive techniques are used in equipment inspection and they can evaluate materials in order to detect the emergence and evolution of flaws that occur due to microstructural changes. Among the non-destructive techniques, ultrasonic is one of the most applied in industrial inspection in order to identify and characterize materials, such as sonic attenuation, elastic constants, corrosion, residual tensions, among others. As stainless steel has an anisotropic structure, its microstructure is responsible for the variation of attenuation and ultrasonic velocities, which can be related to size and orientation of grains. This paper reports a study about the influence of temperature on stainless steel in order to relate sonic attenuation to grain size and the precipitation of secondary phases, to AISI 316L steel and the secondary phases precipitation. For duplex UNS 31803 steel, the study presents only the relation of sonic attenuation to the secondary phases of precipitation, since the relation of sonic attenuation to grain size variation did not show significant changes. The ultrasonic parameter of attenuation as a function of frequency demonstrated to be a useful tool to evaluate microstructure transformations in samples of stainless $316 \mathrm{~L}$ steel and UNS S31803. The experimental procedures used for determining the transversal and longitudinal velocity ultrasonic values were satisfactory and similar when related to theoretical studies. The attenuation was dependent of grain size for 316L. This has not happened with duplex samples, possibly because of the insignificant variation in austenitic grain medium size. In duplex steel, the reduction of austenitic grain size was due to the increase of the ferritic phase, in which the secondary phases are precipitated and are responsible for increased hardness measured by Vickers test.
\end{abstract}

Keywords: Duplex steel. Austenitic steel. Attenuation. Ultrasonic test. 


\section{Introdução}

Os aços inoxidáveis são materiais utilizados na engenharia devido as suas excelentes propriedades mecânicas associadas à elevada resistência a corrosão. Estes materiais possuem um teor de cromo acima de $11 \%$ da composição da liga sendo capazes de formar uma camada passivante de óxido de cromo. Esta camada é responsável pela prevenção da corrosão na superfície do material quando exposto à maioria dos meios normalmente agressivos.

A classificação dos aços inoxidáveis pode ser feita em função da sua microestrutura austenítica, martensítica, ferrítica ou duplex. Dentre os citados, serão avaliados neste trabalho os aços inoxidáveis austeníticos e duplex.

Os aços inoxidáveis austeníticos possuem elementos de liga gamagênicos, como o níquel (Ni), que é responsável pela estabilização da estrutura cristalina (CFC), característica da matriz austenítica. Essa estrutura dá aos austeníticos características não-magnéticas e propriedades como boa soldabilidade e deformabilidade. Podem ser utilizados em ambientes desde temperaturas criogênicas, aplicados nos cilindros que armazenam gases (nitrogênio, hélio entre outros), a temperaturas incandescentes de fornos, (McGUIRE, 2008).

Já os aços inoxidáveis duplex possuem essa denominação por causa da sua estrutura bifásica com quantidades similares de austenita e ferrita. Nesse caso, na produção do aço ocorre a inserção de elementos estabilizadores de austenita numa matriz ferrítica, que é estabilizado pelos elementos de liga alfagênicos (estabilizadores de ferrita), (IMOA, 2009). Essa estrutura dá ao aço duplex excelentes propriedades mecânicas, quando comparados a dos aços inoxidáveis ferríticos, e resistência à corrosão, melhores do que os aços inoxidáveis austeníticos, (ZUCATO et al., 2002). Devido a essas propriedades, os duplex são utilizados em indústrias químicas, nucleares, petroquímicas, celulose, marinhas, entre outros.

Técnicas de avaliação não destrutivas como o ensaio ultrassônico têm sido bastante utilizadas na inspeção de materiais para garantir a integridade estrutural e evitar falhas decorrentes de alterações microestruturais. (SILVA et al., (2009); GÜR et al., (2005); NANEKAR et al., (2003). O elevado grau de anisotropia, heterogeneidade, granulometria grosseira e precipitação de fases intermetálicas, decorrentes de processos térmicos, dificultam a interpretação dos resultados (DONOHUE et al., (1993); GOMES et al., (2007)). A técnica ultrassônica ainda possibilita, numa etapa mais avançada, a aquisição de dados sobre propriedades físicas e químicas dos materiais, pois durante seu percurso no material, as ondas ultrassônicas permitem obter informações importantes, entre outras, a velocidade de propagação, a frequência e a atenuação do material (FONSECA et al., (2009); VASUDEVAN et al., (2002)), assim como em OLIVEIRA et al. (2010) que estudou o conteúdo espectral de corpos de prova em aço inoxidável austenítico $316 \mathrm{~L}$, e o perfil do feixe ultrassonico. Já em OLIVEIRA et al. (2010), a onda ultrassônica tembém foi utilizada para para verificar a atenuação ultrassônica em aços inoxidáveis duplex submetidos a tratamentos isotérmicos.

\section{Fundamentação teórica Aços inoxidáveis austeníticos e duplex}

Os aços inoxidáveis são classificados como materiais de engenharia devido a sua excelente resistência à corrosão atribuída ao alto teor de cromo (acima de 11\%) (SEDRIKS, 1996).

Nos aços inoxidáveis em geral, a resistência à corrosão é fornecida por uma fina camada, conhecida como camada passivante, que é formada por óxido de cromo, gerado pela reação do metal com o ambiente. Normalmente essas camadas são livres de poros. Porém, a sua estabilidade pode ser enfraquecida localmente quando o material é submetido a ambientes severos em presença de íons de cloreto (AYDOGDUL et al., 2006).

Pode-se calcular a resistência à corrosão por pite, Pitting Resistance Equivalent (PRE), segundo a equação 01 (SENATORE et al., 2007):

$$
P R E=\% C r+3,3 *(\% M o)+16 *(\% N)
$$

Para aços inoxidáveis austeníticos, tais como o 316L, o PRE é de 23. Já para os aços duplex, os quais possuem uma estrutura bifásica com quantidades praticamente iguais de austenita e ferrita, o PRE equivale a 33 para o aço mais conhecido comercialmente (UNS S31803). 
Os elementos que compõem as ligas de aços inoxidáveis não somente definem o grau de resistência à corrosão, mas também a estrutura que compõe o material. Estes elementos são capazes de definir a estrutura do material relacionando os elementos gamagênicos, ou estabilizadores de austenita, re- presentado pelo níquel equivalente $\left(\% \mathrm{Ni}_{\text {eq }}\right)$, com os elementos de liga alfagênicos, ou estabilizadores de ferrita, representado pelo cromo equivalente $\left(\% \mathrm{Cr}_{\text {eq }}\right)$, de acordo com o diagrama de Schaeffler (GIRẪ, 2008 e GERZELY, 2003), mostrado na Figura 1 . As equações de $\% \mathrm{Ni}_{\text {eq. }}$ e $\% \mathrm{Cr}_{\text {eq. }}$ são apresentadas nas equações 02 e 03 :

$$
\begin{aligned}
& { }_{0} N i_{\text {eq. }}=\% N i+\% C o+30 *(\% C)+25 *(\% N)+0,5 *(\% M n)+0,3 *(\% C u) \\
& \% C r_{\text {eq. }}=\% C r+2 *(\% S i)+1,5 *(\% M o)+5 *(\% V)+5,5 *(\% A l)+1,75 *(\% N b)+ \\
& 1,5 *(\% T i)+0,75 *(\% W)
\end{aligned}
$$

Na Figura 1, considerando o aço inoxidável duplex UNS S31803 com o $\% \mathrm{Cr}_{\text {eq. }}=27,67$, pela equação 03 , e $\% \mathrm{Ni}_{\text {eq. }}=11,54$, pela equação 02 , de acordo com a composição do aço, e correlacionando ambos os valores no diagrama, obtém-se a composição da microestrutura (40\% de ferrita e $60 \%$ de austenita), justificando os percentuais praticamente iguais de ferrita e austenita, característicos de uma estrutura bifásica em aços inoxidáveis duplex.
A adição de níquel nos aços inoxidáveis melhora a resistência à corrosão em meio oxidante neutro ou fraco, mas aumenta consideravelmente seu custo. Níquel em quantidade suficiente possibilita a estrutura austenítica (CFC) ser retida à temperatura ambiente, (OLIVEIRA, 2003).

Aços inoxidáveis austeníticos são amplamente utilizados em plantas de geração de vapor como materiais de canalização e tubos

Fig. 1 Diagrama Schaeffler: Definição das estruturas microestruturais dos aços pela relação $\mathrm{Ni}_{\text {eq. }}$ e $\mathrm{Cr}_{\text {eq }}$ (GIRÃO, 2008; GERZELY, 2006).

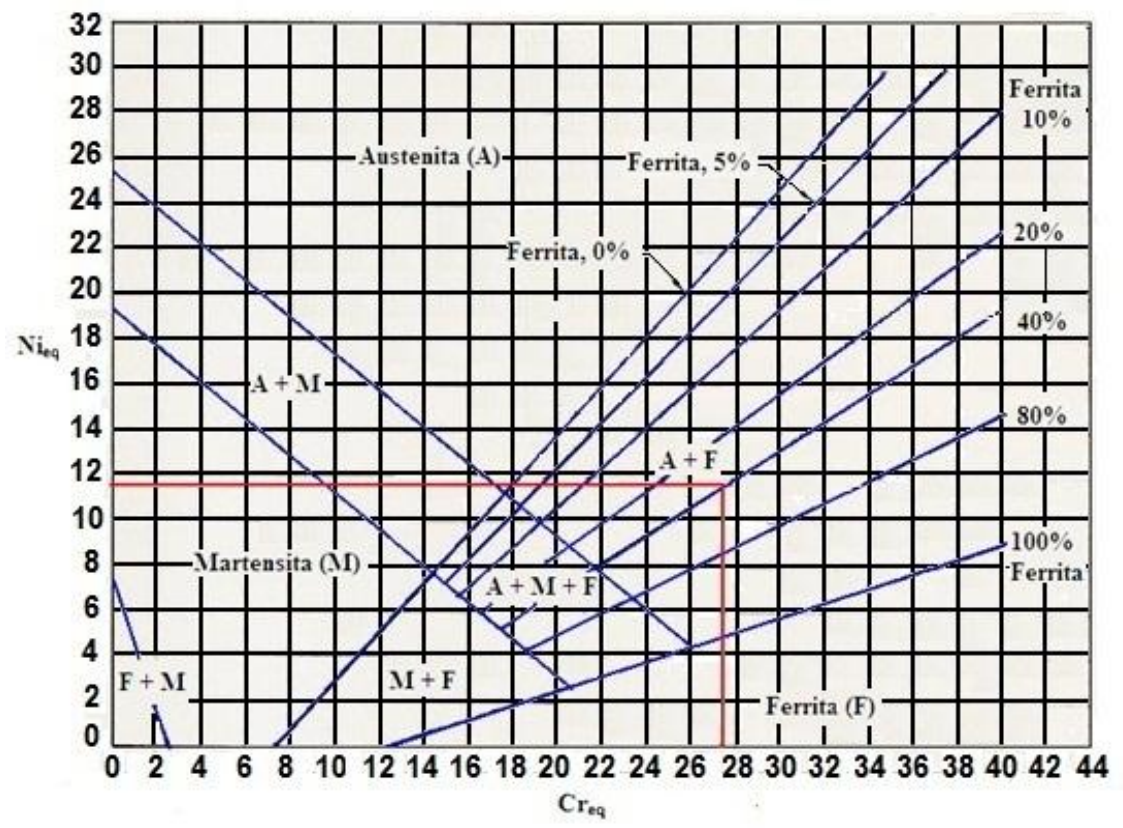


de superaquecimento, devido as suas excelentes propriedades mecânicas e resistência à corrosão em elevadas temperaturas, (AYDOGDUL et al., 2006).

Em relação aos aços duplex, estes possuem uma estrutura de duas fases microestruturais com quantidades praticamente iguais, representadas pela austenita $(\gamma)$ e ferrita $(\alpha)$, conforme dito anteriormente. Essa microestrutura dá a esses aços excelentes propriedades mecânicas e resistência à corrosão, se comparado aos aços correspondentes ferríticos e austeníticos monofásicos. Devido a sua composição ter essencialmente altas concentrações de cromo $(\mathrm{Cr})$ e molibdênio $(\mathrm{Mo})$ favorecem a utilização em ambientes agressivos. Dessa forma, aços inoxidáveis duplex tornam-se bastante competitivos em relação a outros aços inoxidáveis. Devido as suas excelentes propriedades, os aços inoxidáveis duplex são altamente utilizados em indústrias químicas, nucleares, petroquímicas, celulose, marinhas, entre outros (ALBUQUERQUE et al., 2010; FARGAS et al., 2009; SILVA et al., 2009).

\section{Precipitados nos aços inoxidáveis austeníticos e duplex}

Quando aços inoxidáveis austeníticos são submetidos a elevadas temperaturas, como na soldagem, na faixa de temperatura entre $500^{\circ} \mathrm{C}$ e $600^{\circ} \mathrm{C}$, há a quebra de resistência a corrosão intergranular como resultado da segregação de carbonetos de cromo $\left(\mathrm{M}_{3} \mathrm{C}_{26}\right)$. Altas concentrações de partículas de $\mathrm{M}_{3} \mathrm{C}_{26}$ em cromo diminuem localmente o cromo contido na região adjacente a estes precipitados ricos em cromo, (NETTO, 2009).

Além de carbonetos de cromo, a exposição dos aços inoxidáveis austeníticos, como $316 \mathrm{~L}$, a elevadas temperaturas por longos períodos de tempo podem resultar na formação de outras fases (sigma $(\sigma)$, laves $(\eta)$ e chi $(\chi)$ ), conforme mostrado na Figura 2. A formação das fases intermetálicas, a qual é atrasada devido à difusão lenta de elementos substitucionais necessários para sua nucleação e crescimento, resulta na diminuição de cromo $(\mathrm{Cr})$ e molibdênio (Mo) na matriz austenítica. Fase sigma cuja composição química, $\mathrm{FeCr}$, é um problema severo devido aos efeitos prejudiciais nas propriedades mecânicas e resistência a corrosão localizada. Essa fase nucleia nos contornos de grão e é encontrada nos aços austeníticos 316L aproximadamente a $100 \mathrm{~h}$ a $800^{\circ} \mathrm{C}$, conforme observado no diagrama de precipitação de fases, na Figura 2, (AYDOGDUL et al., 2006).

Fig. 2 Precipitação de fases secundárias no aço austenítico 316L (SAHLAOUI, 2004).

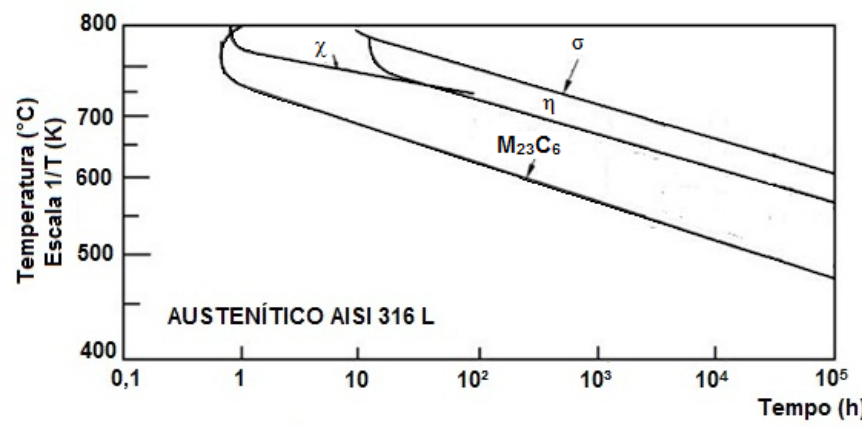

Já para os aços duplex, em contrapartida às suas excelentes propriedades, possuem algumas limitações, como a facilidade para formar precipitados quando são submetidos a ciclos térmicos acima de $300^{\circ} \mathrm{C}$, conforme mostrado na Figura 3 .

Fig. 3 Precipitação de fases secundárias no aço duplex UNS S31803 (SAF 2205) (ZUCATO, 2002).

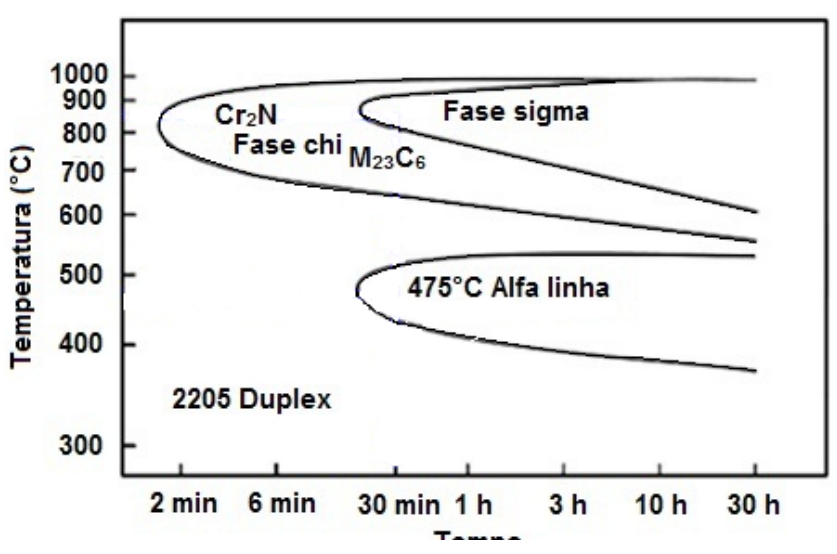

Entre as diversas possibilidades, a formação de fase sigma segue sendo a que merece uma atenção especial, já que possui uma rápida cinética de formação e um forte efeito fragilizante. Esta fase pode aparecer durante resfriamento lento se atravessar a faixa de temperatura entre $600^{\circ} \mathrm{C}$ a $1000^{\circ} \mathrm{C}$, sendo a sua cinética mais rápida a $850^{\circ} \mathrm{C}$. A fase sigma é dura e frágil causando perda de rigidez do aço duplex. Além disso, essa fase consome cromo e molibdênio da matriz, o que leva 
ao esgotamento destes elementos na matriz. Como resultado nas propriedades do aço, a formação da fase é responsável pela perda de resistência à corrosão. A formação dessa fase limita a utilização dos aços duplex em alguns processos de fabricação (produção de tubos grossos e barras de diâmetro grande), o que dificulta a obtenção de forjados com espessuras grandes, e também proporciona a redução de sua vida útil em serviço (FARGAS et al., 2009; ZUCATO et al., 2002; VASCONCELLOS, 2008; ALBUQUERQUE et al., 2010).

Porém, quando os aços duplex são submetidos a temperaturas abaixo de $525^{\circ} \mathrm{C}$, numa faixa entre 425 a $475^{\circ} \mathrm{C}$, ocorre a transformação de fase através da decomposição espinodal para formação da fase $\alpha$, tendo sua cinética mais rápida a $475^{\circ} \mathrm{C}$. (ALBUQUERQUE et al., 2010). Este mecanismo é responsável pela formação da fase $\alpha$ inicial em duas fases, uma fase $\alpha$ pobre em cromo e outra fase $\alpha$ ' rica em cromo. Uma observação a ser feita é que a fase austenita não sofre transformação nesta região (SILVA et al., 2009).

Os aços inoxidáveis, em geral, possuem o diagrama de precipitação de fases secundárias relacionando o tempo de exposição ao qual estão submetidos com a temperatura que está sendo trabalhado, como mostrado nas Figuras 2 e 3. Dessa forma, a Tabela 1 mostra os precipitados que ocorrem nos aços inoxidáveis austeníticos e duplex relacionando-os com a faixa de temperatura que cada um ocorre.

Tabela 1. Principais fases secundárias dos aços austeníticos e duplex

(MILITITSKY, 2008; MARTINS, 2006).

\begin{tabular}{cccc}
\hline \multicolumn{2}{c}{ AUSTENİTICO 316L } & \multicolumn{2}{c}{ DUPLEX UNS S31803 } \\
\hline Fase & $\begin{array}{c}\text { Temperatura de } \\
\text { precipitação }\left({ }^{\circ} \mathrm{C}\right)\end{array}$ & Fase & $\begin{array}{c}\text { Temperatura de } \\
\text { precipitação }\left({ }^{\circ} \mathrm{C}\right)\end{array}$ \\
\hline $\begin{array}{c}\text { Carboneto de ferro } \\
\left(\mathrm{M}_{23} \mathrm{C}_{6}\right)\end{array}$ & $450-750$ & $\begin{array}{c}\text { Carboneto de Ferro } \\
\left(\mathrm{M}_{23} \mathrm{C}_{6}\right)\end{array}$ & $550-900$ \\
Sigma $(\sigma)$ & $650-800$ & Sigma $(\mathrm{FeCr})$ & $650-1000$ \\
Chi $(\chi)$ & $750-800$ & $\alpha$ ' (alto $\mathrm{Cr})$ & $350-750$ \\
Laves $(\eta)$ & $600-750$ & Austenita secundária & $600-1000$ \\
& & Nitreto $\left(\mathrm{Cr}_{2} \mathrm{~N}\right)$ & $550-1000$ \\
\hline
\end{tabular}

\section{imersão \\ Ensaio não destrutivo ultrassônico por}

O ultrassom é largamente utilizado em diversos segmentos industriais, como ferramenta de controle de qualidade, garantindo a integridade de materiais, principalmente na detecção de descontinuidades como trincas, inclusões, defeitos em soldas, entre outros, no interior de materiais que possuam superfícies refletivas (FONSECA, 2009).

A técnica pulso eco por imersão é um método ultrassônico cuja peça a ser inspecionada e o transdutor ficam total ou parcialmente imersos. Durante o ensaio por imersão não existe contato direto do cabeçote com a peça, conforme visto na Figura 4. A transmissão sonora é realizada através de um líquido, usualmente água.
Fig. 4 Ensaio por imersão: Ausência de contato entre transdutor e a peça a ser inspecionada (SANTIN, 2003 e ANDREUCCI, 2008)

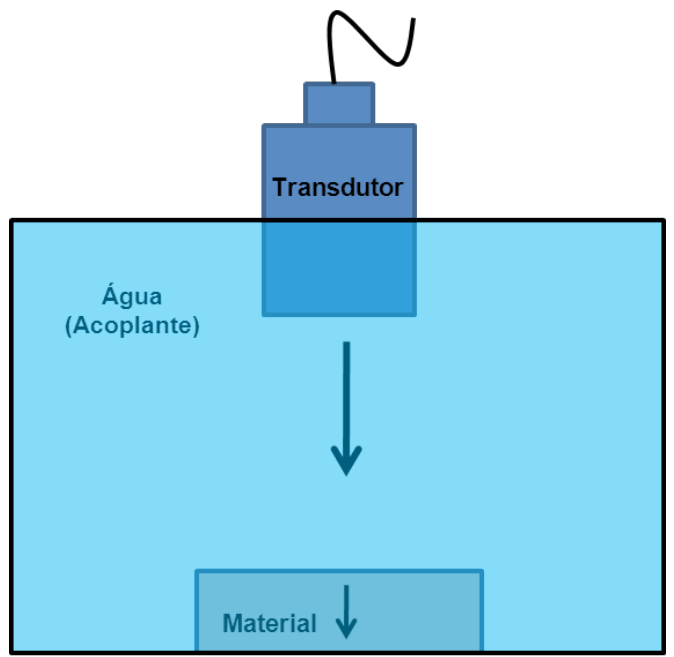


Por não haver contato direto do sensor com o material, durante o ensaio de imersão, o que ocorre é a formação de uma coluna de líquido entre o cabeçote e o material que está sendo inspecionado. Esta coluna permite um acoplamento homogêneo e uniforme garantindo uma boa transmissão acústica (SANTIN, 2003). A coluna d'água é específica de cada tipo de transdutor e deve ser ajustada de modo que o segundo eco da água apareça na tela numa distância superior ao primeiro eco do material, conforme visto na Figura 5 (SANTIN, 2003).

Fig. 5 Visualização A-scan dos ecos de fundo durante ensaio por imersão (ANDREUCCI, 2008).

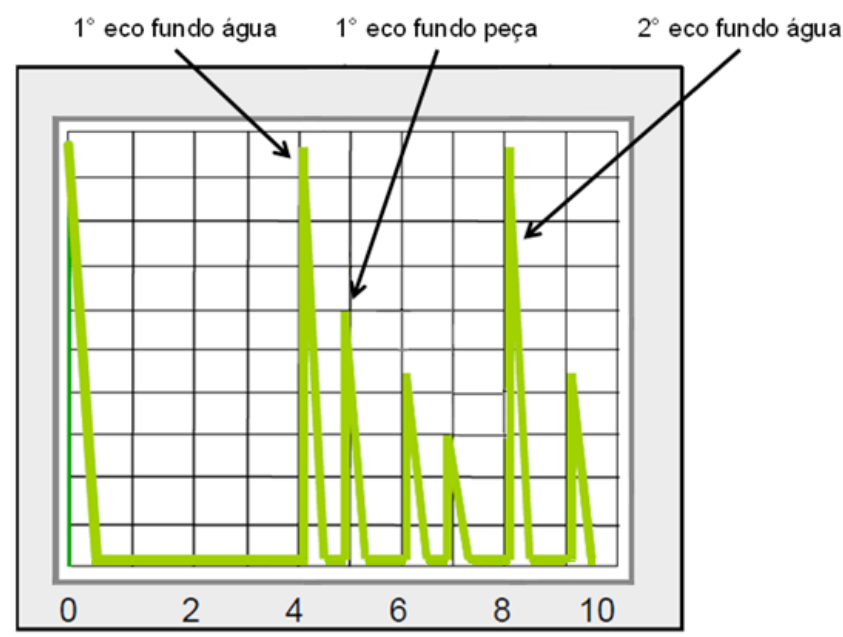

O ensaio por imersão tem como vantagens a velocidade da inspeção e a possibilidade do controle e da direção do feixe sônico através de sistemas automatizados (LOPES et al., 2010).

\section{Atenuação sônica}

A técnica ultrassônica é usada para caracterização de microestruturas, avaliação de defeitos e avaliação de propriedades do material. O uso de medidas ultrassônicas durante a fabricação e tratamento térmico garante a ausência de descontinuidades inaceitáveis e a presença de uma microestrutura desejada e propriedades aceitáveis. Inspeção ultrassônica em serviço é realizada para detectar algumas degradações inaceitáveis na microestrutura e a formação e extensão de defeitos durante a operação de um componente. Parâmetros ultrassônicos como a velocidade e atenuação têm sido correlacionados com as características microestruturais envolvidas durante tratamentos térmicos em aços ferríticos, superligas, ligas de alumínio e alguns outros materiais. Técnicas ultrassônicas são utilizadas para a determinação de limite de resistência, tenacidade à fratura, tamanho de grão e fração volumétrica de fases secundárias (KUMAR et al., 2002).

Conforme SANTIN (2003), o fenômeno da atenuação ocorre quando a intensidade do feixe sônico recebido por um transdutor é menor do que a transmitida no material. Na prática, a atenuação poderá ser visualizada quando existir uma queda de amplitude dos ecos de reflexão proveniente do material a ser inspecionado, o que representa a relação da perda de energia com a distância percorrida pela onda, conforme visto na Figura 6.

Fig. 6 Perda de energia: Visualização através da diminuição da amplitude dos ecos.

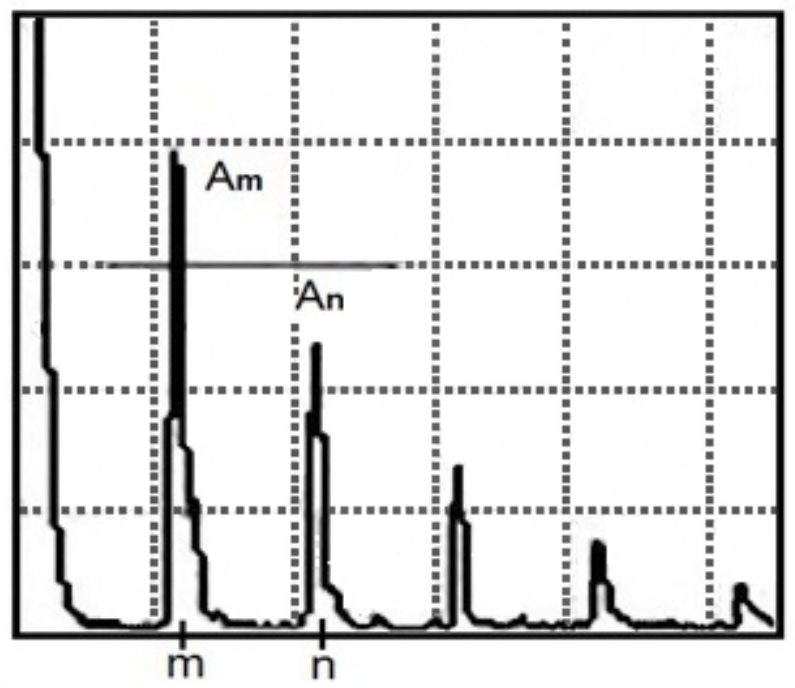

A determinação da atenuação sônica pode ser realizada com base na norma ASTM E 664-93. São exigidos alguns requisitos para a realização do ensaio: a amostra deve ter a espessura maior que o comprimento de onda e o local de inspeção não estar próximo das laterais do corpo de prova. Os sinais ultrassônicos coletados neste ensaio têm que ser processados de forma a efetuar uma comparação entre as amplitudes dos ecos de fundos no domínio da frequência, calculando o coeficiente de atenuação através da equação 04 : 


$$
\operatorname{Atenuação~}(f)=\frac{20 \log _{10}\left(\frac{A_{m(f)}}{A_{n(f)}}\right)}{2 *(n-m) * T}
$$

Onde $\mathrm{n}$ e $\mathrm{m}$ indicam as posições dos ecos, $\mathrm{A}_{\mathrm{m}(\mathrm{f})}$ e $A_{n(f)}$ as amplitudes dos espectros de frequência dos ecos correspondentes e T é a espessura do material, conforme visto na Figura 6.

\section{Metodologia \\ Confecção dos corpos de prova e tratamentos térmicos}

Foram confeccionados seis corpos de prova: três em aço inoxidável austenítico AISI $316 \mathrm{~L}$ (composição: C-0,03\%; Si- 1,00\%; Mn - 2,00\%; P $-0,045 \%$; S - 0,03\%; Cr - 16,00-18,00\%; Mo 2,00-3,00\%; Ni - 10,00-14,00\%) e três corpos de prova em aço inoxidável duplex UNS S31803 (composição: C-0,014\%, $\mathrm{Cr}-22,23 \%, \mathrm{Fpr}-35,34 \%, \mathrm{Mn}$ 1,39, Mo-3,08, N - 0,185, Ni - 5,8, P - 0,022, S $0,0003, \mathrm{Si}-0,41)$. Todos os corpos de prova foram confeccionados com as dimensões (300x75x24) $\mathrm{mm}$, conforme a norma ASTM E 1065. A Tabela 2 exibe as condições as quais foram submetidos cada corpo de prova:

Tabela 2. Relação dos corpos de prova utilizado com os ciclos térmicos.

\begin{tabular}{lccc}
\hline \multicolumn{1}{c}{ Material } & Amostra & Temperatura $\left({ }^{\circ} \mathrm{C}\right)$ & Tempo de exposição \\
\hline \multirow{3}{*}{ Austenitico 316L } & 316L_CR & - & - \\
& 316L_850 & 850 & $30 \mathrm{~min}$ \\
& 316L_1100 & 1100 & $15 \mathrm{~min}$ \\
\hline \multirow{2}{*}{ Duplex UNS } & DP_CR & - & - \\
S31803 & DP_475 & 475 & $30 \mathrm{~min}$ \\
& DP_850 & 850 & $30 \mathrm{~min}$ \\
\hline
\end{tabular}

Estas temperaturas foram escolhidas a fim de comparar o aumento do tamanho de grão (nos aços austeníticos), e o comportamento da precipitação de fases secundárias (nos aços duplex), com o fenômeno da atenuação, conforme descrito no item sobre atenuação sônica. Quanto aos tempos de exposição térmica mostrados na Tabela 2, foram escolhidos tempos de tratamentos térmicos próximos da realidade da duração média de realização de um processo de soldagem.

Para as amostras em aços austeníticos 316L, a atenuação foi comparada com a variação no tamanho de grão, pois conforme visto no diagrama de precipitação de fases (Figura 2), a formação de fases deletérias, como carbonetos de cromo e fase sigma, somente ocorrem sob tempos muito longos. O corpo de prova 316L_CR manteve-se como recebido e os outros dois corpos foram submetidos aos seguintes tratamentos isotérmicos: a temperatura de $850^{\circ} \mathrm{C}$ durante 30 minutos $\left(316 \mathrm{~L} \_850\right)$, para comparação com os aços duplex na mesma temperatura, e a $1100^{\circ} \mathrm{C}$ durante 15 minutos $\left(316 \mathrm{~L} \_1100\right)$, considerando a temperatura de solubilização conforme KUMAR et al.(1999), seguido de resfriamento brusco em água.

Já para as amostras em aço inoxidável duplex, a atenuação foi comparada com o comportamento das precipitações de fases secundárias, mostradas na Figura 6, pois para os aços duplex não há uma variação significativa no tamanho de grão, já que sua estrutura consiste de matriz ferrítica com ilhas de austenita, microestruturas totalmente diferentes entre si. Neste caso o corpo DP_CR não teve exposição a ciclo térmico e nos outros dois (DP_475 e DP_850) foram realizados tratamentos térmicos para precipitação de fases secundárias. O corpo de prova DP_475 foi submetido a um 
tratamento isotérmico a $475^{\circ} \mathrm{C}$ no tempo de 30 min, com o objetivo de encontrar a precipitação da fase $\alpha$, segundo as Figuras 3 e 7, ZUCATO et al. (2002), e, o corpo de prova DP_850 foi exposto a um tratamento isotérmico a $850^{\circ} \mathrm{C}$ por 30 minutos, para verificar a precipitação da fase $\sigma$, caracterizada pelo endurecimento do material. Estas temperaturas foram escolhidas, pois ambas apresentam a cinética de precipitação mais rápida para as suas respectivas fases (MAGNABOSCO, 2009 e ALBUQUERQUE et al.,2010).

Fig. 7 Tempos e temperaturas de exposição das fases sigma e alfa linha (ZUCATO et al., 2002).

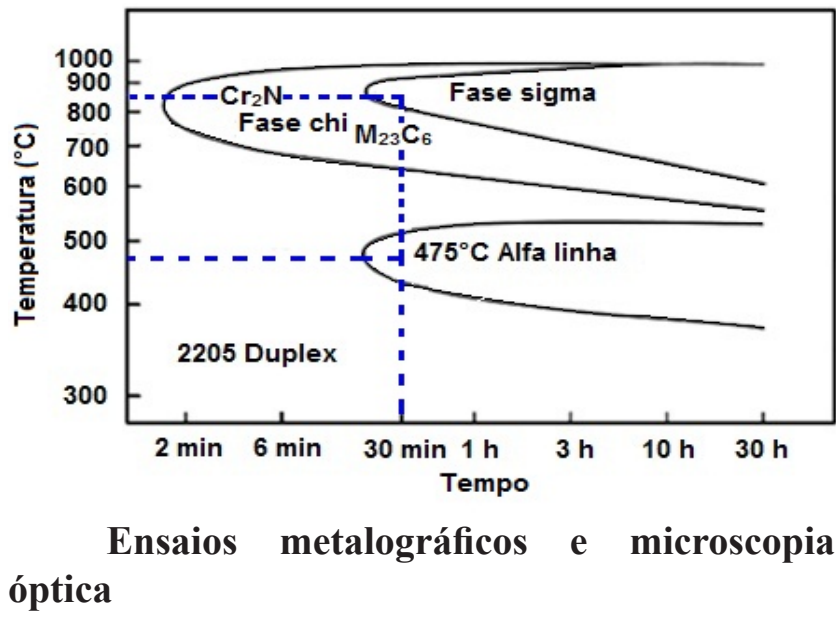

Com a finalidade de observar a variação do tamanho de grão, nos aços austeníticos, e a precipitação de fases deletérias, nos aços duplex, a realização de ensaio metalográfico e a microscopia óptica são métodos importantes para a visualização da microestrutura desses aços.

Para a realização do ensaio metalográfico, as amostras do aço austenítico 316L e aço duplex UNS S31803 foram embutidas em baquelite, lixadas com lixas 220, 320, 400, 600 e 1200 meshes. A seguir, foram polidas com pasta diamante $3 \mu \mathrm{m}$ e $1 \mu \mathrm{m}$. Posteriormente, as amostras do aço austenítico foram atacadas durante 30 segundos em $30 \mathrm{~mL}$ de solução contendo partes iguais de $\mathrm{HCl}, \mathrm{HNO}_{3}$ e água destilada (VANDER VOORT, 1984). Para cada amostra foi possível a visualização homogênea da estrutura austenítica, bem como as alterações no tamanho de grão.

Para as amostras em aço duplex, a denominada DP_CR foi atacada durante 45 segundos com solução Behara, que é produzido por $20 \mathrm{ml}$ de ácido clorídrico $(\mathrm{HCl})$ em $100 \mathrm{ml}$ de $\mathrm{H}_{2} \mathrm{O}$ destilada e adição de $0,6 \mathrm{~g}$ de metabissulfito de potássio $\left(\mathrm{K}_{2} \mathrm{~S}_{2} \mathrm{O}_{5}\right)$, (MOTTA et al., 2009), para revelar os grãos de ferrita, de cor marrom, e austenita, de cor mais clara, na matriz, como visto em MARTINS (2006). Quanto às demais amostras (DP_475 e DP_850), além da aplicação da solução Behara, estas foram posteriormente atacadas pelo reagente Murakami durante 20 segundos. Este reagente é composto de água destilada $\left(\mathrm{H}_{2} \mathrm{O}\right)$, ferricianeto de potássio, $\mathrm{K}_{3} \mathrm{Fe}(\mathrm{CN})_{6}$, e hidróxido de potássio $(\mathrm{KOH})$ numa proporção de 1:1:1, ou seja, foram utilizadas $30 \mathrm{ml}$ de água, 30 $\mathrm{g}$ de ferricianeto de potássio e $30 \mathrm{~g}$ de hidróxido de potássio, para revelar as precipitações de fases, MARTINS (2006). Após esta etapa, um microscópio óptico UNIMET modelo 9117 e uma câmera fotográfica Nikon modelo D50 permitiram a captura e armazenamento das imagens referentes às microestruturas reveladas pelo ensaio.

\section{Ensaio de dureza}

Com o objetivo de caracterização das precipitações de fases secundárias nas amostras de aço inoxidável duplex, foi realizado o ensaio de dureza Vickers, conforme norma ASTM E 92-82, e posteriormente comparados à velocidade ultrassônica longitudinal e transversal, conforme ASTM E 49495. Para a determinação da microdureza nos corpos de prova em aço inoxidável duplex foi utilizado o microdurômetro SHIMADZUC, modelo HMV-2E, com uma força de $10 \mathrm{kgf}$, conforme utilizado por FARGAS et al. (2009).

\section{Determinação do tamanho de grão}

Como parâmetro relevante no fenômeno da atenuação sônica em materiais anisotrópicos, ter ciência do tamanho do grão se torna necessário, visto que são superfícies refletivas que contribuem para a perda de energia no material a ser inspecionado.

A determinação do tamanho de grão para as amostras metalográficas foi efetuada de acordo com a norma ASTM E 112-96. A norma indica o traçado, em direções aleatórias, de linhas retas cujo comprimento total $\mathbf{L}$ seja conhecido $(500 \mathrm{~mm})$. É contabilizado o número de interceptações $\mathbf{P}$ destas 
retas com os contornos de grão. As situações em que ocorre a intercepção de uma junção tripla, este valor é tratado como 1,5. O comprimento total das linhas $\mathbf{L}$ é então dividido pelo total de interceptações $\mathbf{P}$, indicado pelo fator multiplicador $\mathbf{k}(\mathrm{mm})$, empregado na equação 05 :

$$
\mathrm{k}=\frac{L}{P}
$$

O fator multiplicador $\mathrm{k}$ é encontrado em milímetros. A determinação do tamanho de médio do grão (n) em $\mu \mathrm{m}$ é realizada pela relação do k com a escala da imagem metalográfica $(50 \mu \mathrm{m})$, através de uma regra de três simples, conforme descrito abaixo:

Onde:

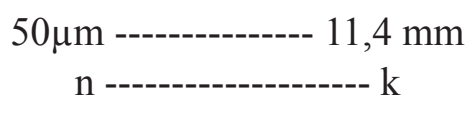

$$
\mathrm{n}=\frac{\mathrm{k} * 50}{11,4}
$$

Para cada condição foram realizadas as medidas em cinco campos distintos.

\section{Velocidades ultrassônicas longitudinal e transversal}

Para avaliar as variações microestruturais e relacionar com os dados de dureza obtidos para o aço duplex, foram calculados os dados de velocidade longitudinal, através de ensaios ultrassônicos pulso eco por contato, utilizando um sensor Krautkrämer $^{\circledR}$, modelo MB-4S, com frequência central de $4 \mathrm{MHz}$; e velocidade transversal com o transdutor de 2,25 MHz da Panametrics ${ }^{\circ}$, através da equação 06, conforme norma ASTM E 494-95, no qual é relacionado a espessura do material (que é conhecida) com o tempo de propagação da onda (visualizado no osciloscópio Tektronix ${ }^{\circledR}$, modelo TDS 2024B). Os sinais foram coletados de forma aleatória através de todo corpo de prova no total.

$$
\mathrm{V}=\frac{2 * \mathrm{e}}{\mathrm{t}}
$$

\section{Ensaio ultrassônico e determinação da ate- nuação sônica}

Para a coleta dos sinais utilizados na obtenção do coeficiente de atenuação, através do ensaio ultrassônico pulso eco por imersão, assim como na determinação da velocidade ultrassônica os sinais foram colhidos de forma aleatória através de todo corpo de prova. Um aparelho de ultrassom da marca Krautkrämer ${ }^{\circ}$, modelo USM 25 foi empregado como um gerador de pulso para o sensor fabricado pela Olympus Panametrics, modelo V303-SU, com frequência central de $1 \mathrm{MHz}$ e diâmetro de 0,5 " (12,5 mm). Foi utilizado um osciloscópio Tektronix ๑, modelo TDS 2024B, para digitalização dos sinais aquisitados pontualmente. Em seguida foram transferidos a um computador para as etapas de processamento digital dos sinais ultrassônicos. Na Figura 8 é visualizado o esquema experimental.

Fig. 8 Esquema experimental do ensaio ultrassônico (JÚNIOR et al., 2010).

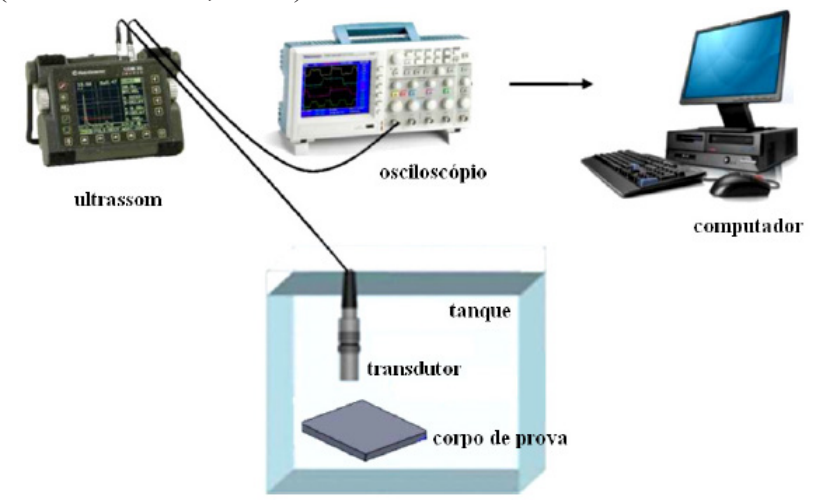

Foram coletados 50 sinais em diferentes posições dos corpos de prova em aço austenítico316 L e duplex UNS S31803. De acordo com a norma ASTM E 664-93, em cada ecograma foram janelados a região com os ecos de reflexão, para os quais foi aplicada a Transformada Rápida de Fourier para a determinação da atenuação como função da frequência.

\section{Resultados e discussões Análise microestrutural}

A microestrutura da amostra em aço austenítico 316L em sua condição como recebido, 316L_CR, pode ser vista na Figura 9. Observa-se que a microestrutura austenítica possui os contornos de grão bem definidos. 
Fig. 9 Microscopia óptica do aço AISI 316L com aumento de (a) 400X e (b) 200X

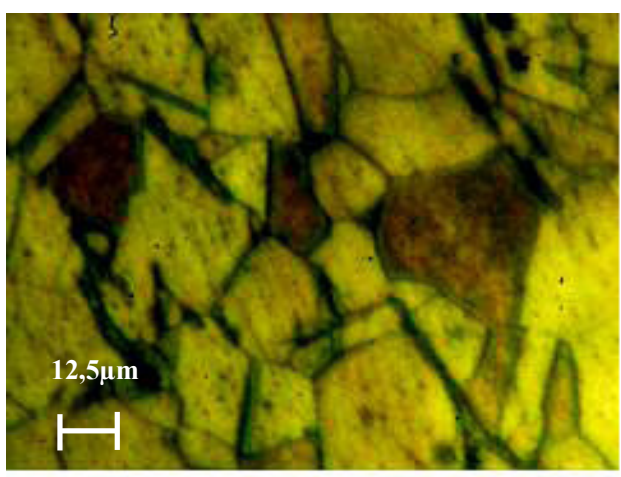

(a)

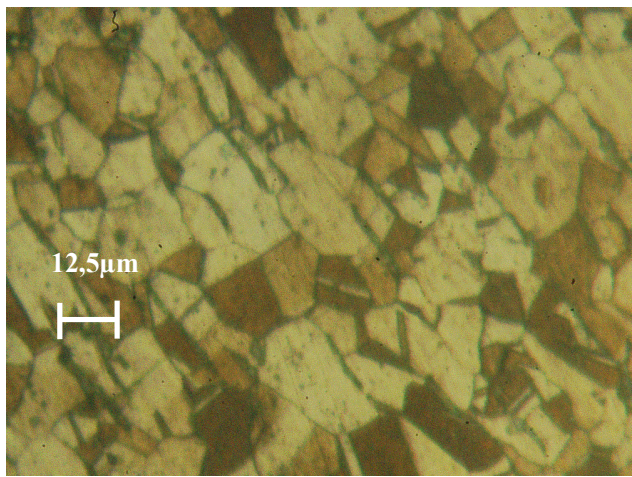

Na Figura 10 é apresentada a microscopia óptica do aço austenítico tratado termicamente a $850^{\circ} \mathrm{C}$ por 30 minutos. Nesta temperatura e tempo de exposição da amostra 316L_850 é possível verificar o aumento do tamanho de grão da matriz austenítica.

Fig. 10 Microscopia óptica do aço AISI 316L tratado isotermicamente a $850^{\circ} \mathrm{C}$ por 30 minutos com aumento de (a) $400 \mathrm{X}$ e (b) $200 \mathrm{X}$

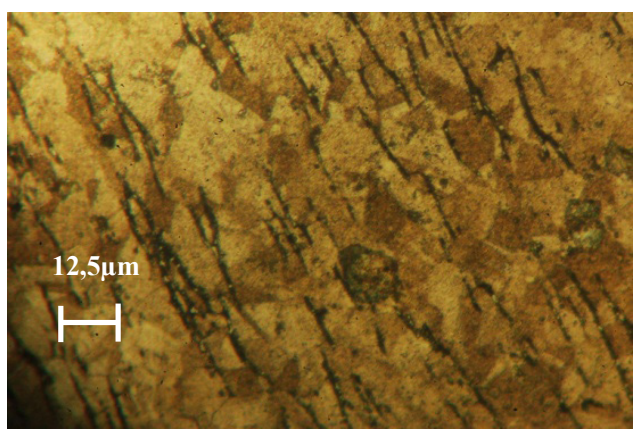

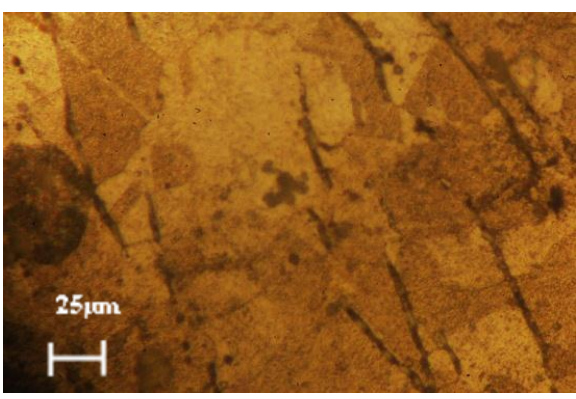

Quando o aço austenítico 316L é tratado termicamente a $1100^{\circ} \mathrm{C}$ por 15 minutos, verifica-se um aumento do tamanho de grão superior às amostras anteriores (316L_CR e 316L_850), conforme citado por Kumar et al. (1999) e visto na Figura 11.

Fig. 11 Microscopia óptica do aço AISI 316L tratado isotermicamente a $1100^{\circ} \mathrm{C}$ por 15 minutos com aumento de (a) $400 \mathrm{X}$ e (b) $200 \mathrm{X}$

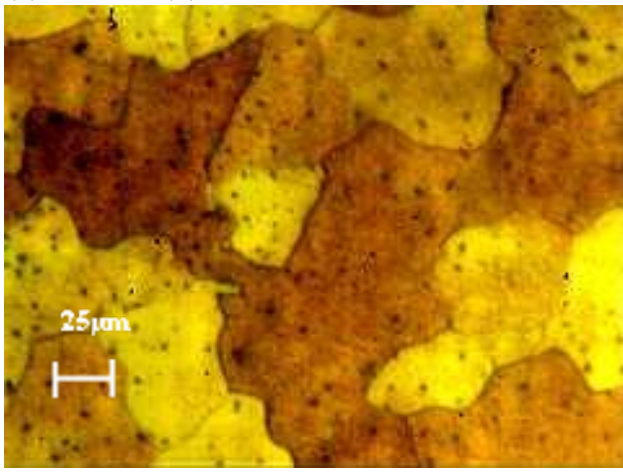

(a)

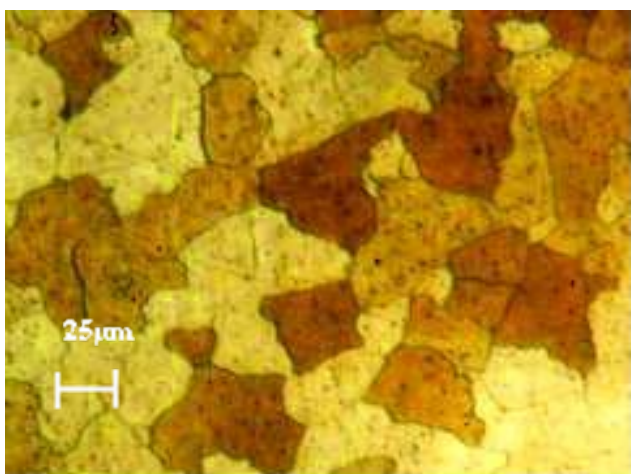

(b)

Para a amostra de aço inoxidável UNS S31803, na condição como recebido, DP CR, a cor mais clara indica a região das ilhas austeníticas e os tons mais escuros, a matriz ferrítica, sem a presença de fases deletérias observáveis por metalografia, como observado na Figura 12. 
Fig. 12 Microscopia óptica do aço UNS S31803 com aumento de (a) 400X e (b) 200X
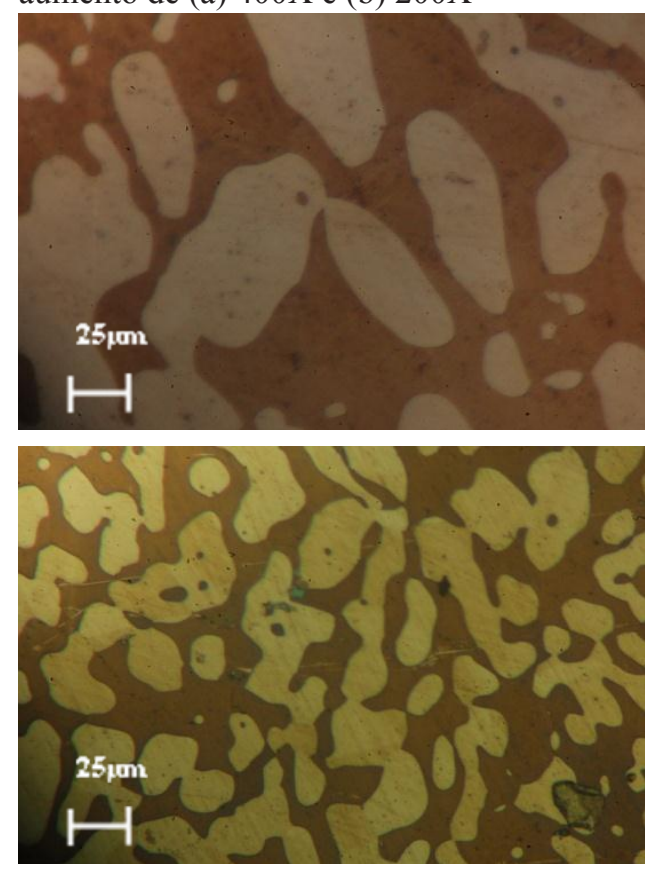

(a)

Na Figura 13, pode ser vista a metalografia do corpo de prova DP_ 475 tratado a $475^{\circ} \mathrm{C}$ por $30 \mathrm{mi}$ nutos, porém a fase secundária característica dessa temperatura, a fase $\alpha$, não é evidenciada, pois ainda não foi desenvolvido um reagente para revelar essa fase, segundo SOUZA et al. (2002).

Fig. 13 Microscopia óptica do aço UNS S31803 tratado isotermicamente a $475^{\circ} \mathrm{C}$ por 30 minutos com aumento de (a) $400 \mathrm{X}$ e (b) $200 \mathrm{X}$
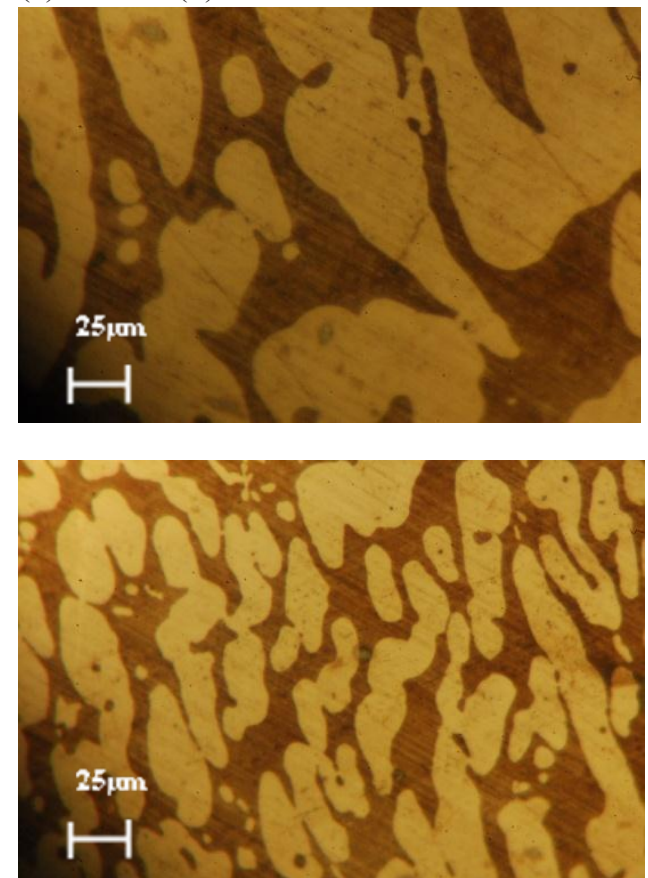

$\mathrm{Na}$ Figura 14, é apresentada a metalografia do corpo de prova DP 850 em aço duplex tratado a $850^{\circ} \mathrm{C}$ por 30 minutos, onde se pode perceber a formação da fase sigma nas interfaces de $\gamma / \alpha$, e o crescimento da mesma para dentro da ferrita $(\alpha)$, como visto em VASCONCELLOS (2008).

Fig. 14 Microscopia óptica do aço UNS S31803 tratado isotermicamente a $850^{\circ} \mathrm{C}$ por 30 minutos com aumento de (a) $400 \mathrm{X}$ e (b) $200 \mathrm{X}$

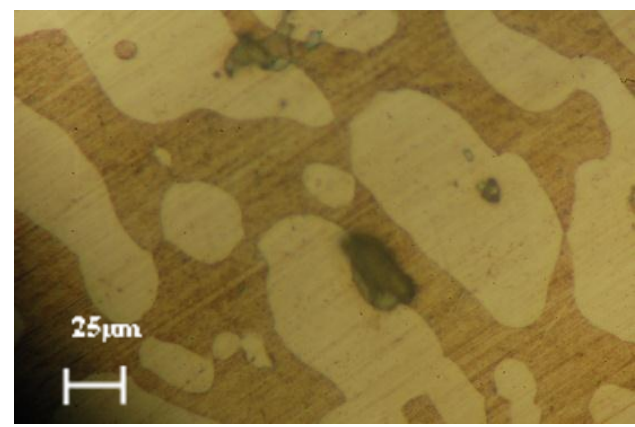

(a)

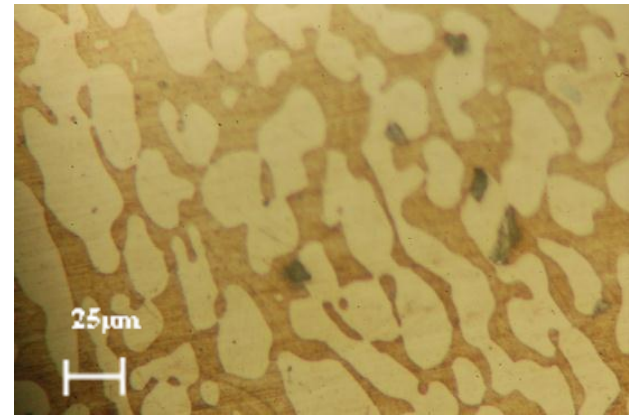

(b)

\section{Parâmetros ultrassônicos e dureza}

Os valores de dureza foram comparados com fatores que podem caracterizar a mudança microestrutural tais como a temperatura de exposição e a velocidade ultrassônica longitudinal e transversal nas amostras em aço duplex.

As velocidades (longitudinal e transversal) foram encontradas através da relação da diferença de dois ecos consecutivos com a espessura do material conhecida, conforme item 3.5. Os valores médios teóricos e práticos desses parâmetros ultrassônicos podem ser visualizados na Tabela 3 . 
Tabela 3. Valores teóricos e práticos (médios) de velocidade longitudinal e transversal em aço inoxidável UNS S31803.

\begin{tabular}{cccccc}
\hline \multirow{2}{*}{ Material } & Amostra & \multicolumn{2}{c}{$\begin{array}{c}\text { Velocidade longitudinal } \\
(\mathrm{m} / \mathrm{s})\end{array}$} & \multicolumn{2}{c}{$\begin{array}{c}\text { Velocidade Transversal } \\
(\mathrm{m} / \mathrm{s})\end{array}$} \\
\cline { 3 - 6 } & & Teórico & Prático & Teórico & Prático \\
\hline \multirow{2}{*}{ Duplex UNS } & DP_CR & 5800 & 5823 & 3100 & 3236 \\
S31803 & DP_475 & $\approx 5800$ & 5803 & $\approx 3100$ & 3213 \\
& DP_850 & $\approx 5800$ & 5813 & $\approx 3100$ & 3216 \\
\hline
\end{tabular}

Conforme visto na Figura 15, o maior valor de dureza corresponde ao corpo de prova DP_475 (temperatura de $475^{\circ} \mathrm{C}$ ) e possivelmente está relacionada à precipitação da fase $\alpha^{\prime}$, como indicado por SOUZA et al. (2002). A velocidade transversal tem o menor valor para a amostra DP_475. O corpo de prova DP_850, caracterizado na Figura 14, apresenta o maior valor para a velocidade transversal e um valor elevado de dureza, porém menor do que o encontrado em DP_475. No corpo de prova DP_CR, considerando o valor da temperatura da sala $\left(25^{\circ} \mathrm{C}\right)$, foi obtido o menor valor de dureza e um valor de velocidade transversal maior do que encontrado em DP_475, conforme descrito em RUIZ et al.(2009)

Fig. 15 Variação da velocidade da onda ultrassônica transversal e dureza com a temperatura de exposição dos corpos de prova

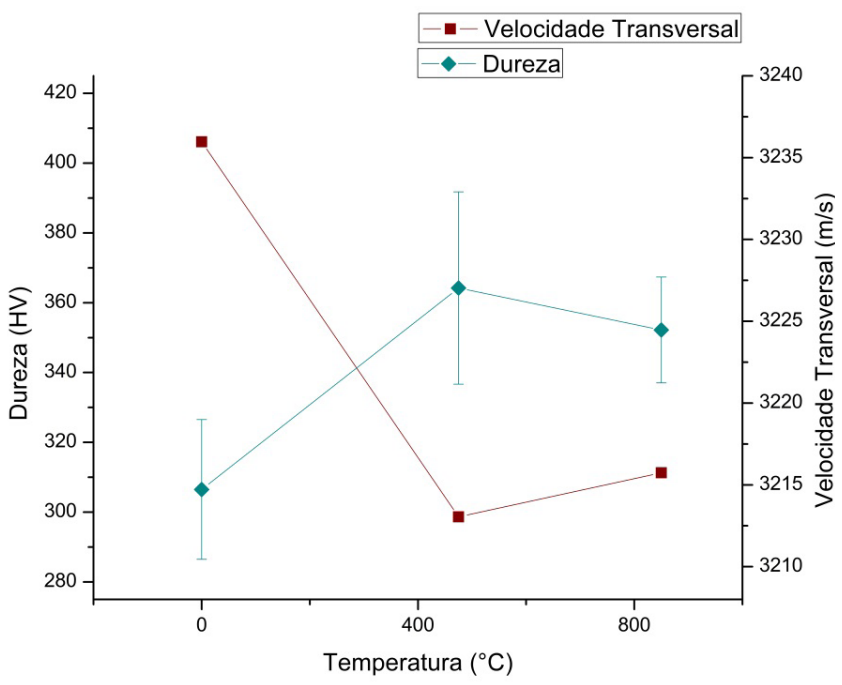

Na Figura 16, a temperatura de exposição é relacionada com a dureza e a velocidade longitudinal. Verifica-se que o maior valor de dureza ocorre também com o corpo de prova DP_475 e que o valor da velocidade longitudinal também é menor nesse ponto. Para a amostra DP_CR é visto que possui o maior valor para velocidade longitudinal e o menor valor de dureza. Já com a amostra DP_850, o valor de dureza é um pouco menor e o valor da velocidade longitudinal supera o valor mostrado para DP_475 como citado por Kutty et al. (1987).

Fig. 16 Variação da velocidade da onda ultrassônica longitudinal e dureza com a temperatura de exposição dos corpos de prova

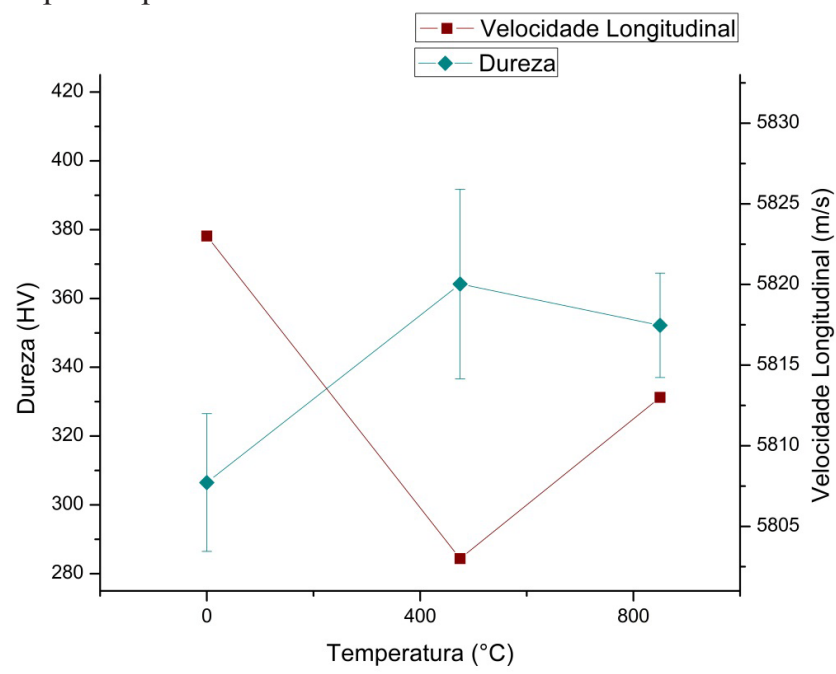

O gráfico da figura 17 relaciona a dureza com as velocidades ultrassônicas, longitudinal e transversal. Observa-se então que ambas as velocidades decrescem com o aumento da dureza, como visto em RUIZ et al. (2009). 
Fig. 17 Variação da velocidade da onda ultrassônica longitudinal e dureza com a temperatura de exposição dos corpos de prova

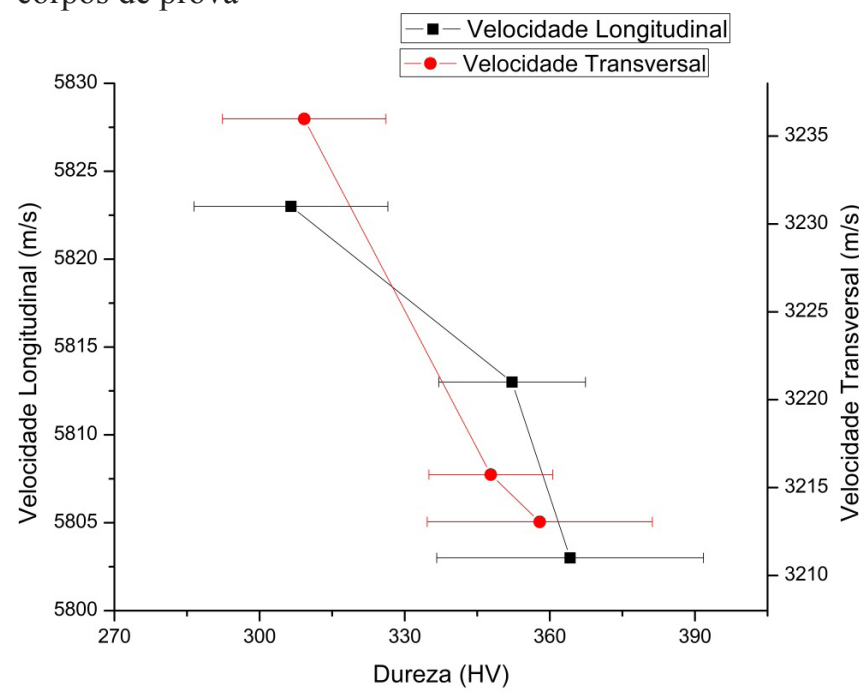

Atenuação, tamanho de grão e precipitados

A Tabela 4 mostra os valores de coeficiente de atenuação para as amostras em aço austenítico 316L e em aço inoxidável duplex UNS S31803, correlacionados com as medidas de tamanho de grão obtidas por meio da norma ASTM E 112-96.

Considerando-se o aumento no tamanho de grão da austenita nas amostras 316L_CR e $316 \mathrm{~L} 1100$, foi verificado que a atenuação mostrou-se dependente, conforme apresentado em KUMAR et al. (1999).

Tabela 4. Resultados dos coeficientes de atenuação

\begin{tabular}{cccc}
\hline Material & $\begin{array}{c}\text { Temperatura } \\
\left({ }^{\circ} \mathrm{C}\right)\end{array}$ & Grain size $(\mu \mathrm{m})$ & $\begin{array}{c}\text { Attenuation coef- } \\
\text { ficient } 1 \mathrm{MHz}(\mathrm{db} / \\
\mathrm{mm})\end{array}$ \\
\hline \multirow{3}{*}{ Austenitico 316L } & Como recebido & $36.16 \pm 6.37$ & 0.0676 \\
& 850 & $33.05 \pm 2.71$ & 0.0717 \\
& 1100 & $73.35 \pm 20.22$ & 0.0720 \\
\hline \multirow{3}{*}{ Duplex UNS S31803 } & Como recebido & $57.65 \pm 9.03$ & 0.0603 \\
& 475 & $54.32 \pm 7.14$ & 0.0561 \\
& 850 & $61.15 \pm 2.15$ & 0.0546 \\
\hline
\end{tabular}

\section{Conclusões}

O parâmetro ultrassônico de atenuação em função da frequência mostrou-se uma ferramenta útil para avaliar as transformações microestruturais das amostras em aço inoxidável austenítico 316L e duplex UNS S31803.

O procedimento experimental utilizado para a determinação das velocidades sônica transversal e longitudinal foi satisfatório quanto aos resultados
Para as amostras DP_CR, DP 475 e DP 850, não houve correlação do tamanho de grão com a atenuação, considerando as variações insignificantes quanto ao diâmetro médio do grão da austenita. RUIZ et al. (2009) indica que a complexidade dos mecanismos de transformação da ferrita para o aço UNS S31803, entre outros fatores, contribuem para a redução do coeficiente de atenuação. Dentre estes mecanismos, a formação de novos contornos de grão da fase $\alpha$ em um tempo curto de exposição à temperatura do ciclo isotérmico permite caracterizar as transformações da matriz ferrítica que afeta as propriedades do aço inoxidável duplex, bem como a precipitação de fases secundárias, nestas temperaturas, principalmente alfa linha e sigma. A redução do tamanho de grão austenítico significa um aumento da fase ferrítica, onde são precipitadas as fases secundárias responsáveis pelo aumento da dureza detectada pelo ensaio Vickers.

Em relação aos desvios padrões encontrados para as amostras, foi observado que o maior valor de desvio ocorre na amostra que está solubilizada (316L_1100), o que é justificado pela homogeneidade da amostra. Já o menor valor de desvio padrão tem valores similares na mesma temperatura em ambos os aços (316L_850 e DP_850) provavelmente devido à similaridade do comportamento do tamanho de grão austenítico nestas amostras. encontrados, ao serem confrontados com os teóricos.

Os valores obtidos no ensaio de microdureza para as amostras em aço duplex indicaram a presença da formação de fase $\alpha$ ' para o corpo de prova DP_475, não observável por microscopia óptica, e também permitiu correlacionar a dureza com os valores de velocidade de propagação do ultrassom nos corpos de prova DP_CR, DP 475 e DP 850 .

Já a determinação do grão se fez importante, pois para as amostras em aço austenítico $\left(316 \mathrm{~L} \_\mathrm{CR}\right.$ 
e 316L_1100), a atenuação sônica mostrou-se dependente do tamanho do grão, justificando a perda de energia do material. Para as amostras em duplex, não houve correlação do tamanho de grão com a atenuação, devido a não haver variações significantes quanto ao diâmetro médio do grão da austenita. Dessa forma, a complexidade dos mecanismos de transformação da ferrita (precipitação de fases secundárias) para o aço UNS S31803, dentre outros fatores, contribuem para a redução do coeficiente de atenuação. A redução do tamanho de grão austenítico significa um aumento da fase ferrítica, onde são precipitadas as fases secundárias responsáveis pelo aumento da dureza detectada pelo ensaio Vickers.

\section{Agradecimentos}

Este trabalho foi apoiado pelo Conselho Nacional de Desenvolvimento Científico e Tecnológico (CNPq) e Fundação de Amparo à Pesquisa do Estado da Bahia (FAPESB) através do Instituto Federal de Educação, Ciência e Tecnologia da Bahia (IFBA) e Grupo de Pesquisa em Ensaios Não Destrutivos (GPEND).

\section{Referências:}

ALBuQuerque, V. H. C., SILVA, E. M., LEITE, J. P., MOURA, E. P., FREITAS, V. L. A., TAVARES, J. M. R. S. Spinodal decomposition mechanism study on the duplex stainless steel UNS S31803 using ultrasonic speed measurements. Materials and Design Elsevier, v.31, p. 2147-50, 2010.

ANDREUCCI, R. Ensaio por ultrassom: aplicação Industrial. Apostila Abende, Ed. julho, 2008.

ASTM INTERNATIONAL E 1065. Standard Guide for Evaluation Characteristics of Ultrasonic Search Units. 2003.

ASTM INTERNATIONAL E 112-96. Standard Test for Determining Average Grain Size. 2003.

ASTM INTERNATIONAL E 664-93. Standard Practice for the Measurement of the Apparent Attenuation of Longitudinal Ultrasonic Waves by Immersion Method, 2003.

ASTM INTERNATIONAL E 92-82. Standard Test Method for Vickers Hardness of Metallic Materials. 2003.

ASTM INTERNATIONAL E 494-95. Standard Practice for Measuring Ultrasonic Velocity in Materials. 2003.
AYDOĞDUL, G. H., AYDINOL, M. K. Determination of susceptibility to intergranular corrosion and electrochemical reactivation behaviour of AISI 316L type stainless steel. Corrosion Science, v.48, 3565-83, Mar, 2006.

DONOHUE, K. D.; BRESSLER, J. M.; VARGHESE, T.; BILGUTAY, N. M.; Spectral correlation in ultrasonic pulse echo signal processing. Ultrasonics, v.40, p. 330-37, Jul, 1993.

FARGAS, G.; MESTRA, A.; ANGLADA, A. M. Influencia de la fase sigma en la resistencia al desgaste de los aceros inoxidables dúplex. MECANICA DE LA FRACTURA, 26. Anales. 2009.

FONSECA, E. Determinação indireta das propriedades mecânicas de aço ASTM A36 laminado com o uso de ultrassom. Dissertação (Mestre em Engenharia), Escola de Engenharia, Programa de Pós-Graduação em Engenharia de Minas, Metalúrgica e de Materiais, Universidade Federal do Rio Grande do Sul, Porto Alegre, 2009.

GERZELY, R. D. P. Evolução da fração volumétrica de ferrita durante a formação de fase sigma do aço SAF 2205. Relatório final orientado pelo Prof. Dr. Rodrigo Magnabosco - Departamento de Engenharia Mecânica - FEI, 2003.

GIRÃO, I. F. Caracterização da resistência a corrosão por pite do aço UNS S31803 após soldagem. Projeto de pesquisa orientado pelo Prof. Dr. Rodrigo Magnabosco, Centro de Desenvolvimento de Materiais Metálicos (CDMatM) Departamento de Engenharia Mecânica Centro Universitário da Fundação Educacional Inaciana Pe. Sabóia de Medeiros (FEI), São Bernardo do Campo, 2008.

GOMES, M. S. B. S.; NÓBREGA, L. H. M. S.; SILVA, E. S.; SANTOS, N. C.; Estudo da correlação entre microestrutura e velocidade sônica de um aço 1045 tratado termicamente. João Pessoa: CONNEPI, 2007.

GÜR, C. H.; TUNCER, B. O. Characterization of microstructural phases of steels by sound velocity measurement. Materials Characterization, v.55, p.160-66, May, 2005.

JÚNIOR, I. R.; PEREIRA, L.; RIBEIRO, I.; FARIAS, C. T.; SOBRAL, M. D.; PARANHOS, R. J. Estudo da atenuação sônica em aços inoxidáveis. Maceió: CONNEPI, 2010.

KUMAR, A.; JAYAKUMAR, T.; PALANICHAMY, P.; RAJ, $B$. Influence of grain size on ultrasonic spectral parameters in AISI type 316 stainless steel. Scripta Materialia, v. 40, n. 3, p. 333-340, 1999.

.; LAHA, K.; JAYAKUMAR, T.; RAO, K. B. S.; RAJ, B. Comprehensive microstructural characterization im modified 9Cr-1Mo ferritic steel by ultrasonic measurements. Metallurgical and Materials Transactions A, v.33A, 2002. 
KUTTY, T. R. G.; CHANDRASEKHARAN, K. N.; PANAKKAL, J. P.; GHOSAL, S. K.; DE, P. K. Use of ultrasonic velocity for nondestructive evaluation of ferrite content in duplex stainless steels. NDT International 20 - 6 p. 361, 1987.

LOPES, J.; RIBEIRO, I.; FARIAS, C.; SANTOS, Y. T.; OLIVEIRA, M. Mapeamento da perda de espessura por corrosão em tubo de aço utilizando ensaio não destrutivo ultrassônico através da técnica de imersão $\boldsymbol{B} \boldsymbol{B} B \boldsymbol{B} L E \boldsymbol{R}, 2010$.

MAGNABOSCO, R. Kinetics of sigma phase formation in a duplex stainless steel. Materials Research, v.12, n.3, p.321327,2009

MARTINS, M. Caracterização microestrutural-mecânica e resistência à corrosão do aço inoxidável superduplex ASTM A890 / A890M Grau 6a . Tese de Doutorado em Ciências e Engenharia dos Materiais, USP, 2006

McGUIRE, F. M. Stainless steels for design engineers. ASM International, 2008. p. 69-90

MILITITSKY, M. Development and characterization of nickel free austenitic stainless steel. Belgium: Editora University Gent, 2008

MOTTA, T. M.; FARIAS, C. T. T.; SANTOS, E. T. F.; SOBRAL, M. D. C., PEREIRA, M.; RIBEIRO, I. S. Determinação das velocidades sônicas em aço superduplex exposto a diferentes tratamentos térmicos. Belém/PA: CONNEPI, 2009.

NANEKAR, P. P.; SHAH, B. K.; Characterization of material properties by ultrasonics. National Seminar on Non-Destructive Evaluation, NDE 2003, Trivandrum, India.

NETTO, H. V. C. Influência da temperatura de ensaio e de tratamento térmico na resistência à corrosão por pite dos aços inoxidáveis austeníticos AISI 304 e AISI 316. Projeto de Graduação, Vitória, 2009.

OLIVEIRA, A. P. N.; Apostila: fundamento de engenharia de materiais. Florianópolis, março de 2003. Disponível em: $\quad<$ http://www.scribd.com/doc/921108/Microsoft-WordSmith-cap7-A > Acesso em: 01 dez. 2012.

OLIVEIRA, T. A. S.; FARIAS, C. T. T.; OLIVEIRA, M. A.; SANTOS, Y. T. B.; SOBRAL, M. D. C. Estudo da influência da temperatura na atenuação do sinal ultrassônico em aços inoxidáveis AISI 316L e duplex UNS S31803 submetido a tratamento isotérmico. CONFERENCIA SOBRE TECNOLOGIA DE EQUIPAMENTOS, 11, Ipojuca, 2011.

OLIVEIRA, M. A.; FARIAS, C. T. T.; SANTOS, Y. T. B.; OLIVEIRA, T. A. S.; RIBEIRO, I. S.; SOBRAL, M. D. C.; BARRA, S. R. Estudo do conteúdo espectral e perfil do feixe ultrassônico em aço inoxidável 316L submetido a diferentes ciclos isotérmicos. CONGRESSO NACIONAL DE ENSAIOS NÃO DESTRUTIVOS E INSPEÇÃO, 28. Anais... Santos, 2010.
PRATICAL guidelines for the fabrication of duplex stainless steels. 2.ed. London: International Molybdenum Association (IMOA), 2009 Disponível: <www.imoa.info/ files/stainless steel/Duplex Stainless Steel 2d Edition.pdf $\_$Acesso em: 15 fev. 2013

RUIZ, A.; ORTIZ, N.; CARREÓN, H.; RUBIO, C. Utilization of ultrasonic measurements for determining the variations in microstructure of thermally degraded 2205 duplex stainless steel. Journal of Non Destructive Evaluation, v.28, p. 131139, 2009.

SAHLAOUI, H.; MAKHLOUF, K.; SIDHOM, H.; PHILIBERT, J. Effects of ageing conditions on the precipitates evolution, chromium depletion and intergranular corrosion susceptibility of AISI 316L: experimental and modeling results. v.372, issues 1-2, pages 98-108, 2004.

SANTIN, J. L. Ultrassom técnica e aplicação. 2 ed. Consultoria Pró END, 2003.

SEDRIKS, A. J. Corrosion of stainless steels. 2 ed. New York: Chichester; Brisbane: John Wiley, 1996.

SENATORE, M.; FINZETTO, L.; PEREA, E. Estudo comparativo entre os aços inoxidáveis duplex e os aços inoxidáveis AISI 304L/316L. REM: R. Esc. Minas, Ouro Preto, v.60, n.1, p.175-81, 2007.

SILVA, E. M.; ALBUQUERQUE, V. H. C.; LEITE, J. P.; VARELA, A. C. G.; MOURA, E. P.; TAVARES, J. M. R. S. Phase transformations evaluation on a UNS S31803 duplex stainless steel based on nondestructive testing. Materials Science and Engineering, A 516, p.126-30, Mar, 2009.

SOUZA, A. J.; REGO, G. J. A.; ABREU, H. F. G.; Estudo comparativo dos aços AISI 316 $\mathrm{L}$ e duplex submetidos à faixa de temperatura de $380^{\circ} \mathrm{C} \mathrm{a} 480^{\circ} \mathrm{C}$ usado em trocador de calor. CONAMENT/SAM-SIMPOSIO MATERIA, 2002.

VANDER VOORT, G. F. Metallography: principles and practice. New York: Mc-Graw Hill, 1984.

VASCONCELLOS, P. I. G. Soldagem em campo de tubos de aço inox duplex e superduplex. Tese de Mestrado, Universidade Estadual do Norte Fluminense - UENF, 2008.

VASUDEVAN, M.; PALANICHAMY, P. Characterization of microstructural changes during annealing of cold worked austenitic stainless steel using velocity measurements and correlation with mechanical properties. Journal of Materials Engineering and Performance, v.11, n.2, p. 169-79, Apr, 2002 .

ZUCATO, I.; MOREIRA, M. C.; MACHADO, I. F.; LEBRÃO, S. M. G. Microstructural characterization and the effect of phase transformations on toughness of the UNS S31803 duplex stainless steel aged treated at $850{ }^{\circ} \mathrm{C}$. Materials Research, v.5, n.3, p. 385-389, Jul, 2002. 